\title{
Serão as consultas de dez minutos parte do passado?
}

Joana Gonçalo Meireles Pinto ${ }^{1}$

\section{RESUMO}

Ainda que presente em todas as especialidades médicas, a prestação de cuidados de saúde centrados no doente traduz uma das seis competências nucleares da disciplina de medicina geral e familiar. Esta competência implica desenvolver e aplicar uma técnica de consulta que promova o estabelecimento de uma relação médico-doente efetiva, com respeito pela autonomia e circunstâncias dos utentes. Atualmente são várias as pressões externas presentes na prática clínica de um médico de família, sendo as consultas de dez minutos apenas um exemplo. Com este artigo pretende-se refletir sobre o possível impacto que as consultas de dez minutos poderão ter na relação médico-doente, nos profissionais, mas também na segurança dos atos médicos prestados.

Palavras-chave: Medicina geral e familiar; Tempos de consulta.

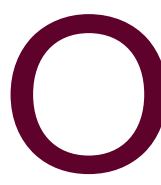
direito à proteção da saúde apenas teve consagração constitucional expressa no ordenamento jurídico nacional na Constituição da República Portuguesa de 1976, mais concretamente no seu artigo $64 .{ }^{\circ}$. De acordo com este artigo, todos têm direito à proteção da sua saúde, assim como o dever de a defender e promover, cabendo ao Estado garantir esse direito através da criação de um serviço nacional de saúde, de caráter universal, compreensivo e tendencialmente gratuito. ${ }^{1}$ Apesar de já anteriormente existirem instituições com responsabilidade de prestação de cuidados de saúde (e políticas de saúde), toda a sua filosofia de organização tinha como foco a desresponsabilização do Estado na assistência da doença (recorde-se que se tratavam sobretudo de instituições de caráter religioso, como as Misericórdias). Com a elaboração deste artigo introduziram-se os fundamentos legais que justificaram mais tarde, em 1979, a criação e normalização do Serviço Nacional de Saúde (SNS): cobertura de seguro completa, quer em tipo de cuidados de saúde abrangidos, quer em grau de cobertura de risco, quer na população incluída nesse seguro. Quanto à cobertura universal, sabe-se que esse tipo de acesso a cuidados de saúde só pode ser assegurado através dos cuidados de saúde primários (CSP). Estes, não

1. Médica Interna de Medicina Geral e Familiar. USF São Martinho, ACeS Vale do Sousa Sul, Tâmega II. Penafiel, Portugal. só estão fisicamente próximos das populações que servem, como atuam, cada vez mais, segundo critérios de custo-efetividade garantidos pela existência de equipas multiprofissionais e seguimento adequado dos utentes. Compreende-se, desta forma, que ao ser a especialidade médica orientada para os CSP, a medicina geral e familiar (MGF) assume-se como pedra basilar do SNS.

Ainda assim, assegurar cuidados de saúde custo-efetivos, operando numa lógica de proximidade, não é o único objetivo dos médicos de família. Ainda que presente em todas as especialidades médicas, a prestação de cuidados de saúde centrados no doente traduz uma das seis competências nucleares da disciplina de $\mathrm{MGF}^{2}$ Esta competência implica desenvolver e aplicar uma técnica de consulta que promova o estabelecimento de uma relação médico-doente efetiva, com respeito pela autonomia e contexto das circunstâncias dos utentes. É talvez nesta relação, estabelecida ao longo de vários encontros e não raramente por múltiplos anos, que reside a maior riqueza e especificidade dos profissionais de MGF.

Foi precisamente a preocupação pela relação médico-doente, que tanto estimo, o principal vetor responsável pela elaboração do presente artigo. Questiono-me se não serão as consultas de dez minutos, adotadas em tantas unidades de CSP, uma ameaça real à concretização e/ ou manutenção desta relação. Não será, aliás, possível que conduzam a piores resultados em saúde? 
Tornou-se, assim, importante refletir sobre que motivos justificaram a implementação de consultas médicas de dez minutos, mas, mais importante do que isso, quais as implicações que tais consultas poderão trazer para os doentes e profissionais de saúde.

Quando se pretende determinar tempos padrão de consultas médicas são vários os fatores a considerar, sendo alguns exemplos: dados relativos à experiência nacional e internacional; tipo de consulta (primeira ou subsequente); complexidade da doença ou do doente; análise da história clínica (entrevista centrada no doente e no médico); exame físico; avaliação biopsicossocial (uma outra competência nuclear de MGF); explicação da situação clínica, exames auxiliares de diagnóstico e potenciais propostas terapêuticas ao doente (e familiares, sempre que aplicável); partilha da decisão terapêutica com o doente; esclarecimento de eventuais dúvidas; obtenção do consentimento informado, livre e esclarecido; complexidade e morosidade da utilização dos sistemas informáticos; necessidade de realizar relatórios ou preencher documentos em papel (levando muitas vezes à duplicação de informação); eventual presença de estudantes ou médicos em formação, assim como a realização de procedimentos próprios à especialidade durante a consulta. ${ }^{2-3}$

\section{COMO JUSTIFICAR A EXISTÊNCIA DE CONSULTAS DE DEZ MINUTOS?}

São várias as razões que poderão ter condicionado uma diminuição gradual dos tempos mínimos de consulta, designadamente o aumento do número de utentes e das suas necessidades em saúde. A criação de consultas mais curtas implicaria mais consultas por igual período de trabalho e tendencialmente mais utentes com acesso a cuidados de saúde em tempo útil.

Para além disso, no caso particular dos CSP, tem-se verificado a transição gradual da prestação de certos cuidados, outrora exclusivamente hospitalares, para as unidades de CSP, o que naturalmente justifica um maior volume de patologias/atos médicos desempenhados agora por estes profissionais (considere-se, como exemplo, as consultas de hipocoagulação, entretanto disponibilizadas em algumas unidades).

Por outro lado, e não menos importante, o próprio papel atribuído aos CSP no SNS poderá justificar o porquê da criação e adoção destas consultas. Será, aliás, um erro não considerar como pertinente para esta discussão que o comportamento e as decisões dos médicos especialistas em MGF têm impacto em todo o sistema de saúde (o qual, em Portugal, é maioritariamente representado pelo SNS). Para além de serem, na generalidade das vezes, o primeiro ponto de contacto do utente com o SNS, os CSP são também os responsáveis pela orientação dos doentes dentro do próprio SNS (na terminologia anglo-saxónica, este papel é denominado gatekeeping) - só assim se concretiza a postura desejável de advogado dos doentes. ${ }^{4}$ Ao ser o primeiro ponto de contacto dos utentes com o SNS, um maior número de consultas tenderá a dar resposta a um maior número de utentes, situação particularmente importante quando a resolução do problema exige observação por outro profissional de saúde, nomeadamente a nível hospitalar. Desta forma, e sendo a referenciação dos utentes para cuidados mais especializados uma responsabilidade dos médicos de família, com um maior volume de consultas médicas reduzir-se-á, tendencialmente, o tempo necessário até esses cuidados serem prestados.

Também questões inerentes à própria organização dos CSP em Portugal poderão ter contribuído para a normalização destas consultas. A criação das Unidades de Saúde Familiar, no âmbito da reforma dos CSP em Portugal, introduziu pela primeira vez uma flexibilidade de organização e gestão face à estrutura dos centros de saúde tradicionais. Adicionalmente, também o sistema de retribuição foi alterado, passando a ter uma componente baseada na atividade desenvolvida. ${ }^{4}$ Por este motivo, atendendo a esta nova organização, a presença de indução de procura não poderá ser automaticamente descartada. Isto é, a possibilidade da realização de consultas de dez em dez minutos poderá cumprir propósitos economicistas (em que se realizam atos que não são absolutamente necessários segundo a melhor prática clínica, mas que permitem às unidades maiores rendimentos; priorização pela escolha dos médicos como principais executores de certas intervenções, nem sempre da sua competência exclusiva e que poderiam ser desempenhadas por outros profissionais de saúde, como os enfermeiros; listas de utentes sucessivamente maiores). Contudo, atendendo a que são os utentes quem habitualmente solicita o tipo de consultas em que a política dos dez minutos mais 
frequentemente se aplica (as comummente designadas consultas abertas), este efeito poderá ser desprezível.

Assim, e apesar de acreditar que possam ter um propósito social positivo, em MGF as consultas de breves minutos (nas quais se incluem as consultas de dez minutos) mostram-se cada vez mais desadequadas: não só no seu propósito fundamental - servir adequadamente o doente - como também por se parecerem acompanhar de efeitos negativos nos próprios profissionais.

\section{QUE MOTIVOS JUSTIFICAM A INADEQUAÇÃO DAS CONSULTAS MÉDICAS DE DEZ MINUTOS?}

São vários os argumentos que podem ser utilizados para justificar a inconveniência destas consultas médicas, ainda que estas se destinem maioritariamente à gestão da doença aguda.

De todos, talvez o envelhecimento da população se apresente como o mais importante fator impeditivo à generalização das consultas de dez minutos. Com uma população envelhecida, o número de utentes idosos pertencentes à lista de cada médico será cada vez maior. Como esta população apresenta maiores necessidades em saúde é previsível que não só solicitem mais consultas, como cada uma delas seja mais complexa e, consequentemente, mais demorada. Sendo assim, se dez minutos poderão ser suficientes em algumas (poucas) situações, também é verdade que quando se trata de um idoso, de uma criança ou de um utente pouco frequentador/pertencente à lista de outro médico da unidade, esses minutos mostram-se claramente insuficientes, podendo no limite comprometer a qualidade do serviço prestado.

Para além disso, tem-se verificado (e ainda bem) níveis crescentes de exigência nos utentes, não só no que diz respeito à gestão da sua saúde (com maior envolvimento nas decisões médicas e, como tal, abandono progressivo da versão paternalista da medicina) como também à gestão do seu tempo. Sobre este último aspeto, é verdade que a disponibilidade dos utentes em esperar é cada vez menor, facto que poderá afetar negativamente os seus níveis de satisfação. No caso particular dos serviços de saúde existe assimetria de informação e, como tal, muitas vezes a qualidade dos serviços médicos prestados é avaliada pelos doentes com recurso a elementos tangíveis (desde as características físicas das instalações ou do vestuário médico à empatia dos profissionais, ao tempo dispensado pelo médico em cada consulta, até ao tempo passado na sala de espera) e não de acordo com resultados em saúde. Desta forma, ao proceder a agendamentos de dez em dez minutos, não só a própria duração da consulta se revelará insuficiente para o doente (que, por exemplo, tendo a expectativa de abordar vários problemas na mesma consulta, verá alguns deles agendados para encontros posteriores) como também para o médico, condicionando atrasos no agendamento e inevitáveis impactos na satisfação dos utentes. Poder-se-ia, talvez, ao falar do setor da saúde, ser levado a pensar que a satisfação dos utentes é um aspeto menor, já que o mais importante são os resultados efetivos em saúde (por outras palavras, o mais importante é de facto tratar os doentes). Contudo, devemos estar conscientes que os níveis de satisfação são já uma métrica de avaliação económica em saúde bastante valorizada e em amplo desenvolvimento. ${ }^{5}$

Para além dos desafios já descritos, o impacto nos profissionais desta tipologia de consulta não deverá também ser ignorado. ${ }^{6}$ Existe evidência que a adoção de tal periodicidade de consultas poderá contribuir para o burnout do médico, em parte por se sentir menos preparado para lidar com situações mais complexas devido ao constrangimento temporal. Também maiores taxas de prescrição de antibióticos (em parte motivada pela menor disponibilidade do médico em gerir as expectativas do doente em relação à necessidade de prescrição de antibióticos) ou presença de polimedicação poderão ser desencadeadas por tempos mais curtos de consulta. ${ }^{7-8}$

Os desafios gerados por consultas de dez minutos têm sido objeto de análise e reflexão. De facto, a Ordem dos Médicos, de acordo com as recomendações técnicas dos Colégios das Especialidades e das Secções das Subespecialidades, viu-se na necessidade de elaborar um regulamento sobre os tempos padrão das consultas médicas. ${ }^{3}$ Segundo este documento, e relativamente à especialidade da MGF, pode constatar-se que quinze minutos é o tempo mínimo recomendado para consultas médicas presenciais (nomeadamente no caso das consultas por doença aguda, vulgarmente designadas consultas abertas). Desta forma, e apesar de a 
situação ideal passar pela adaptação do tempo de consulta à complexidade e objetivos essenciais de cada uma das diferentes tipologias de consulta, o limiar mínimo de quinze minutos assinala a desadequação que as consultas de dez, onze minutos ou qualquer valor inferior a esse limiar têm nos dias de hoje.

Mas esta preocupação não é exclusiva da realidade portuguesa. No Reino Unido, um dos países em que os CSP desempenham, desde os seus primórdios, um papel preponderante no SNS inglês, as consultas de MGF/clínica geral duram em média 9,2 minutos e em cada uma delas são abordados em média 2,5 problemas médicos. ${ }^{9}$ Esta imposição parece estar a afetar negativamente não só os profissionais como a qualidade dos serviços prestados aos utentes. De acordo com o relatório anual do General Medical Council, 35\% dos médicos inquiridos afirmou ter realizado uma referenciação desnecessária no último ano, fundamentalmente devido ao elevado volume de trabalho diário. Para além disso, mais de um terço dos médicos participantes no inquérito reconheceu não ter sido capaz de prestar o melhor aconselhamento médico devido aos constrangimentos provocados pelos escassos tempos de consulta. ${ }^{10}$ Por este motivo, o Royal College of General Practitioners defende que até 2030 seja adotado o limite mínimo de quinze minutos para todas as consultas médicas realizadas em regime presencial. ${ }^{11}$

Finalmente, e caso se verifique a adoção dos tempos mínimos recomendados nas consultas de CSP, com a consequente extinção das consultas de dez minutos, poder-se-á pensar que o acesso dos doentes aos cuidados de saúde ficará comprometido. Mas será mesmo esse o caso?

São inúmeros os problemas enfrentados atualmente pelo SNS, mas talvez o acesso seja um dos mais significativos e prioritários. Por acesso compreende-se não só a possibilidade de aceder à prestação de cuidados de saúde, como também de os receber com oportunidade, de forma adequada à situação e de modo não discriminatório (portanto, equitativo). Em Portugal há já evidência que aponta para a existência de importantes necessidades em saúde não respondidas pelo SNS - os pagamentos diretos (na terminologia anglo-saxónica assumem a designação de out-of-pocket payments) têm apresentado uma tendência de aumento e representaram, no ano de 2016, 27,8\% da despesa total em saúde em Portugal. Esta contribuição percentual foi claramente superior à média dos países da Europa (18,3\%) ou dos 15 a 20\% recomendados como valor limiar máximo a partir do qual o acesso poderá estar a ser restringido apenas a pessoas que o possam pagar. ${ }^{12}$ Também a percentagem de portugueses com seguros tem aumentado, reduzindo-se a função de proteção financeira desejável do SNS.

Sendo a orientação do doente dentro do SNS um dos papéis dos CSP em Portugal, seria lícito questionar se ao prolongar o tempo destinado a cada consulta e, consequentemente, atendendo menos doentes por período de trabalho se poderiam agravar as questões relativas ao acesso. Mas será o agendamento de consultas mais breves nos CSP a solução? Ou, contraditoriamente, ao facultar ao médico de família mais tempo em cada consulta não se estará a contribuir para a possibilidade de tratamento de situações de saúde mais complexas, poupando os hospitais para situações que impliquem verdadeiramente níveis mais diferenciados de cuidados? Não se conseguirá, desta forma, contribuir para a melhoria da educação para a saúde, muitas vezes negligenciada em consulta por falta de tempo?

São inúmeros os desafios presentes na prática atual da medicina, desde a burocratização dos serviços médicos ao aumento do volume de doentes, às exigências contratuais ou imposições externas, como os menores tempos de consulta, que comprometem a qualidade da relação médico-doente e, no limite, a segurança do ato médico. Assim, pela defesa das obrigações ético-deontológicas, mas também para que a verdadeira participação e inclusão do cidadão enquanto elemento central dos cuidados possa ter lugar, não será melhor considerar as consultas de dez minutos parte do passado?

\section{REFERÊNCIAS BIBLIOGRÁFICAS}

1. Decreto de aprovação da Constituição da República Portuguesa, de 10 de abril de 1976. Diário da República. $1^{\text {a }}$ Série(86).

2. Allen J, Gay B, Crebolder H, Heyrman J, Svab I, Ram P, et al. A definição europeia de medicina geral e familiar (clínica geral/medicina familiar) [The European definition of family medicine (general practice/family medicine)]. Rev Port Med Geral Fam. 2005;21(5):511-6. Portuguese

3. Regulamento n. ${ }^{\circ} 724 / 2019$, de 17 de setembro. Diário da República.

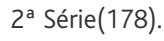

4. Barros PP. Economia da saúde: conceitos e comportamentos. $3^{\mathrm{a}}$ ed. Coimbra: Almedina; 2013. ISBN 9789724053745

5. Carrus B, Cordina J, GretzW, Neher K. Measuring the patient experience: lessons from other industries [homepage]. McKinsey \& CO; 2015. Avai- 
lable from: https://healthcare.mckinsey.com/measuring-patient-experience-lessons-other-industries/

6. Teixeira $C$, Magalhães D, Nóbrega A. Medicina geral e familiar com tempo e cabeça. Rev Ordem Med. 2019;(203):56-7.

7. Irving G, Neves AL, Dambha-Miller H, Oishi A, Tagashira H, Verho A, et al. International variations in primary care physician consultation time: a systematic review of 67 countries. BMJ Open. 2017;7(10):e017902.

8. Wang KY, Seed P, Schofield P, Ibrahim S, Ashworth M. Which practices are high antibiotic prescribers? A cross-sectional analysis. $\mathrm{Br} J \mathrm{Gen}$ Pract. 2009;59(567):e315-20.

9. Salisbury H. Helen Salisbury: the 10 minute appointment. BMJ. 2019; 365:12389.

10. General Medical Council. The state of medical education and practice in the UK [Internet]. London: GMC; 2019. Available from: https://www. gmc-uk.org/-/media/documents/somep-2019---full-report_pdf81131156.pdf

11. Royal College of General Practitioners. Fit for the future: a vision for general practice [Internet]. London: RCGP; 2019. Available from:
https://www.rcgp.org.uk/-/media/Files/News/2019/RCGP-fit-for-thefuture-report-may-2019.ashx?la=en

12. OECD/European Union. Health at a glance: Europe 2018 (state of health in the EU cycle). Paris: OECD Publishing; 2018. Available from: https://ec.europa.eu/health/state/glance/editions/health_glance_ 2018_pt

\section{CONFLITO DE INTERESSES}

A autora declara não possuir quaisquer conflitos de interesse.

\section{ENDEREÇO PARA CORRESPONDÊNCIA}

Joana Gonçalo Meireles Pinto

E-mail: joanapinto_goncalo@hotmail.com

http://orcid.org/0000-0002-5762-846X

Recebido em 20-05-2020

Aceite para publicação em 31-10-2020

\section{ABSTRACT}

\section{SHOULD TEN-MINUTE APPOINTMENTS BE PART OF THE PAST?}

A person-centered approach is one of the core competencies in family medicine. To provide this type of care, specialists in Family Medicine should know and apply the methodology that allows the development of an effective doctor-patient relationship, with respect for the patient's autonomy and circumstances. Currently, there are several external factors that can compromise the quality of medical care, with 10-minute appointments being just an example. This article aims to reflect on the possible impact of this shorter length type of appointments, not just on the doctor-patient relationships, but also on the safety of care and physician workload and stress levels.

Keywords: Family practice; Appointments and schedules; Appointment length; Consultation time. 